\title{
CRIME SCRIPTING: A SYSTEMATIC REVIEW
}

\author{
HASHEM DEHGHANNIRI ${ }^{1,2}$, and HERVÉ BORRION ${ }^{2}$ \\ 1 Cyber Technology Institute, De Montfort University—UK \\ ${ }^{2}$ Department of Security and Crime Science, UCL_UK
}

KEYWORDS: crime script, crime commission process, modus operandi, scenario, situational crime prevention

More than two decades after the publication of Cornish's seminal work about the scripttheoretic approach to crime analysis, this article examines how the concept has been applied in our community. The study provides evidence confirming that the approach is increasingly popular; and takes stock of crime scripting practices through a systematic review of over one hundred scripts published between 1994 and 2018. The results offer the first comprehensive picture of this approach, and highlights new directions for those interested in using data from cyber-systems and the Internet of Things to develop effective situational crime prevention measures.

Hashem Dehghanniri is a Lecturer at the Cyber Technology Institute, De Montfort University. Dr Hervé Borrion is an Associate Professor at the UCL Department of Security and Crime Science. 


\section{Background}

There exist many approaches to crime reduction. Whilst the majority concentrates on the propensity to commit crime, situational crime prevention (hereinafter SCP) operates by altering potential offenders' judgments of risk and reward. Specifically, it seeks to deter them from taking certain courses of action by influencing their perception of opportunities, typically at or near the time and place of its envisaged commission (Clarke, 1997). Twenty-five SCP techniques have been distinguished, such as changing the perceived effort, reward, and viable excuses associated with the translation of opportunity into criminal action (Bullock, Clarke, \& Tilley, 2010). Supported by a raft of empirical studies, Clarke (2009, p. 3) has claimed that those techniques have been successfully applied to a wide variety of crimes including organised crime and terrorism and could, with the necessary ingenuity, be applied across the whole spectrum of crime.

For efficacy, interventions must be tailored to the crimes they are meant to address ( Goldstein, 1979). For this reason, practitioners are encouraged to formulate and analyse problems before settling on a response (Borrion et al., 2019). To reduce crime risks in public space, for instance, problem-solving models recommend analysts to collect data that can assist in identifying the crime events likely to occur in such settings, model the sequences of activities that form their crime commission processes, determine the situational conditions that permit or facilitate them, settle on the environmental conditions within which offenders are likely to operate, and identify factors that influence their decisions to commit certain crimes, substitute one offence for another or desist from any further criminal action (Cornish \& Clarke, 2003) . 
Conscious that the development of crime-specific interventions requires a detailed understanding of the factors influencing decisions to commit crime, Cornish introduced the script-theoretic approach to crime analysis: 'a way of generating, organising, and systematizing knowledge about the procedural aspects and procedural requirements of crime commission' (Cornish, 1994a, 1994b) . In essence, crime scripts are models that describe 'sequences of predictable actions, locations, and roles that constitute [crime] events' (Bennett, 1993). They were recently described by Ekblom and Gill (2015) as 'abstracted descriptions of a particular kind of behavioural process, namely structured sequences of behaviour extended over time and perhaps space, which could be considered functionally self-contained units or subunits of longer sequences'.

The script-theoretic approach has a lot to offer to crime analysts. Studies have referred to it as a tool for eliciting the offender's behaviour and the rationale for their decisions (Beauregard \& Martineau, 2015; Beauregard, Proulx, Rossmo, Leclerc, \& Allaire, 2007; Brookman, Bennett, Hochstetler, \& Copes, 2011; Chiu, Leclerc, \& Townsley, 2011; Gamman, Thorpe, Malpass, \& Liparova, 2012; Hagan, \& Levi, 2004; Hobbs, Winlow, Hadfield, \& Lister, 2005; Lavorgna, 2015; Lord, \& Levi 2017; Meijerink, 2013; Meyer, 2013; Meyer, Jore, \& Johansen, 2015; Willison, 2008; Willison \& Siponen, 2006; Wortley \& Mazerolle, 2013), and others highlighted its utility in organising existing knowledge about the requirements of crime commission such as the skills or resources that criminals need to deploy in order to execute a crime (Balemba \& Beauregard, 2013; Basamanowicz, 2011; Bichler, Bush, \& Malm, 2013; Cornish, 1994b; De Vries, 2012, 2013; Gilmour, 2014; Le, 2013; Leontiadis, 2014; Meijerink, 2013).

As with many techniques, the practice of crime scripting practice has happened rather organically, with limited top-down guidance or coordination between researchers. More than two decades after the publication of Cornish's seminal article, we believe it is now time to draw a contemporary picture of crime scripting practices. The first 
objective of this study was to test the claim that the script-theoretic approach has been increasingly popular in recent years (see Ekblom \& Gill, 2015; Leclerc, 2013, 2017). If confirmed, this trend would be an indicator for one or both of two reasons: it might imply that more empirical examples are now available to demonstrate the use of this approach as a potential crime reduction tool, and/or it might reflect an expansion of the crime script community, and encourage others to learn and apply this approach.

The second objective of this study was to compile a list of references that crime analysts could consult to find scripts. As time goes by, it is becoming increasingly difficult to keep track of what types of crime have been scripted and hence to identify existing gaps. Although illustrative lists can be found in the literature (e.g., Borrion, 2013; Leclerc, 2013), none of them represents an exhaustive resource. As a result, certain crime scripts may not be used (if analysts are unaware of their existence) and knowledge gaps are still difficult to identify. By compiling the first comprehensive catalogue of relevant publications, this work can therefore enhance the impact of published research and stimulate new developments in this field.

The third objective of this review was to take stock of crime scripting practices. Whilst there is no unique scripting method (Brayley, Cockbain, \& Laycock, 2011), little is known about the diversity of methods used. For this reason, we decided to examine how researchers identify relevant data sources, select visualisation models, and assess the scripts they generate. Carefully analysed, this information can be used to create guidelines and training materials for crime reduction practitioners, identify methodological issues, and ultimately support the development of high-quality crime scripts. 
The fourth objective of this study was to identify synonyms of the term 'crime script' that are used by those familiar with Cornish's work. In engineering, for example, similar concepts - use cases and business process models - have been proposed several decades ago to represent how socio-technological systems work and how users interact within them (Claus, Ehrig, \& Rozenberg, 1979). Identifying those will help raise awareness about the knowledge, models, techniques, and tools that could be borrowed from other fields to improve the quality of crime scripts.

\section{Method}

\section{Overall approach}

To take stock of crime scripting practices, we have conducted a systematic review of relevant studies published between $1^{\text {st }}$ January 1994 and $31^{\text {st }}$ December 2018. Systematic reviews are commonly used in the field of crime prevention (e.g. Bowers, Johnson, Guerette, Summers, \& Poynton, 2011; Sidebottom, Tompson, Thornton, Bullock, Tilley, \& Bowers, 2015; Snook, Eastwood, Gendreau, Goggin, \& Cullen, 2007), and are generally considered well suited to produce up-to-date summaries of studies in an area, give an objective collation of results, and produce reliable recommendations (Gough, Oliver, \& Thomas, 2012). This research was conducted following the stages typically found in systematic reviews (e.g. Gough, Oliver, \& Thomas, 2012; Keele 2007; Wright, Brand, Dunn, \& Spindler, 2007) : Formulating the Objectives, Searching the Literature, Literature Selection, Data Extraction and Data Analysis. 


\section{Formulating the objectives}

As mentioned in the previous section, the four questions investigated in this work relate to the diffusion and application of this approach within but also beyond criminology:

1. Has the script-theoretic approach gained traction since Cornish's seminal article was published?

2. What types of crime have been scripted during that period?

3. What methods have been used to generate and evaluate crime scripts?

4. Under what other names are crime scripts known in other disciplines?

\section{Searching the literature}

The search was conducted through two mechanisms: 1) keyword search (using the wildcard term 'crime script") of relevant data sources including grey literature and dissertation databases, and 2) forward citation search based on the primary article in his area: (Cornish, 1994b). The search spans the period starting with the publication of this article and ending in 2018. As shown in Figure 1, thirteen electronic databases were searched: ASSIA (Applied Social Sciences Index and Abstracts), $\mathrm{CINCH}$ (Australian Criminology Database), Criminal Justice Database (ProQuest), ERIC (Education Resources Information Center), IBSS (International Bibliography of Social Sciences), NCJRS (National Criminal Justice Reference Service), ProQuest theses and dissertations, PsycINFO, PsycEXTRA, SCOPUS, Social Policy and Practice, Sociological Abstracts, and Web of Science. In addition, three other data sources were used that include Link.springer, Oxford Journals, and Wiley Online Library. These were used in similar projects (e.g. Bowers, Johnson, Guerette, Summers, \& Poynton, 2010, 2011; Johnson, Tilley, \& Bowers, 2015; Sidebottom, Tompson, Thornton, 
Bullock, Tilley, \& Bowers, 2015) or were flagged when searching through multidisciplinary search engines such as British Library Explorer and Google Scholar. Despite criticisms regarding the use of Google Scholar in systematic reviews (see Boeker, Vach, \& Motschall, 2013), we decided to use it to conduct a forward citation search because the main article, Cornish (1994b), was not available in any of the above data sources.

\section{Literature selection}

Three inclusion criteria were adopted to screen the identified publications:

- Criterion 1: The publication is written in English.

- Criterion 2: The publication contains the word 'script' in its body AND make a nonmarginal reference to crime scripts.

- Criterion 3: The publication concerns the procedural aspects or procedural requirements of crime, as defined in Cornish (1994b).

The first criterion was introduced because of our limited language skills and our lack of confidence in the results generated by a translating tool (e.g., Google Translate) However, this decision was considered acceptable after a search on Google Scholar established that $92 \%$ of the articles identified are written in English. The search was repeated two years later that corroborated these results. Furthermore, some of the articles discarded due to the first criterion may have been translated into English, in which case they would be included in our results. The second criterion allowed a wide range of publications to be considered (including those referring to the terms 'script', 'crime script', 'script-theoretic approach', 'cognitive script', 'offense script' or 'crime commission script'), whilst excluding publications in which these terms only appear in a footnote or reference. The third criterion was used to discriminate between the different meanings of the term 'crime script', and discard the publications that have no 
direct semantic relation to Cornish's approach, especially those concerning 'movie scripts' or 'news scripts' (e.g. Gilliam Jr \& lyengar, 2000) .

\section{Data extraction and analysis}

Publications and authors: All the publications selected in the screening stage were then reviewed by one of the authors, and the following data extracted: study title, publication date and author name. We counted the annual number of manuscripts published in the period of interest, and generated two cumulative frequency distributions that represent the number of relevant publications each year (see Figure 2). In addition, the list of publications was used to estimate the size of the community by calculating the number of authors who have published on this topic over time.

Crime types: The types of crime discussed in the selected studies were identified in the title or abstract, or, when they were not found there, in the body of the articles. We also searched for presence of crime scripts within the shortlisted articles. This was done by searching for synonyms of the term 'crime script' and looking for diagrams, figures, tables, or narratives that describe a crime commission process. For every identified article that contains a crime script, both authors independently recorded the type of crime that was modelled, and discussed them when the results were different. For this, we used a typology inspired from the categories of offenses used in the British Crime Survey (ONS, 2015). For convenience, we included corruption and fraud scripts within the same category, and did the same for theft and robbery offenses. As seen in the results section, some of the scripts can be associated with multiple categories (e.g., fraud offenses causing environmental damage). 
Data sources and visualisation models: The articles containing an original crime script were examined by both authors, and the data sources and visualisation models that were adopted compiled into a list. Data sources were characterised based on their origins (e.g. primary or secondary data) and types (e.g. police report, newspaper article).

Verification and Validation: Information concerning the quality assessment of crime scripts was gathered by searching for possible variants of the words verification, validation, assessment, and evaluation (verif*, valid*, assess*, evaluat ${ }^{*}$ ) in the publications that contain an original crime script. The extracted information was then thematically classified based on the criteria proposed by Borrion (2013). New elements, where appropriate, would be added to the list.

Synonyms: Synonyms of the term 'crime script' were identified in an iterative manner, as suggested by Holton (2007). First, synonyms (e.g., offense script) were identified in (Cornish, 1994b). A list of related keywords (e.g. offense) was then generated based on those, and used (in conjunction with a wildcard character) to identify additional synonyms (e.g. offen*) within the selected articles. When a synonym was found that contained a new term (e.g. scenario in the expression offending scenario), the latter was added to the list of keywords and all selected studies were searched again. 


\section{Results}

\section{Search results}

The search tactics described above returned 889 publications. The aforementioned criteria were then applied to the identified studies, resulting in the inclusion of 416 studies, as shown in Figure 1.

$<$ Add Figure 1 here $>$

Four hundred seventy-three publications were excluded from this study. As explained earlier, 74 of them were written in languages other than English. The three main identified non-English languages were French (22, 30\%), Dutch (18, 24\%), and Italian $(11,15 \%)$. Twenty-three other publications (written in German, Spanish, Chinese, Portuguese, Finnish, Korean, Swedish, Bosnian, Czech, and Greek) were discarded.

\section{Has the script-theoretic approach gained traction since Cornish's seminal article was published?}

Figure 2 is a cumulative frequency diagram showing the number of publications directly related to crime scripts between 1994 and 2018. It confirms that the number of publications has increased more rapidly in recent years. Over half of the publications $(52 \%)$ were recorded in the last five years. One hundred fourteen publications contain a crime script. Within those, we identified 105 original scripts in 85 of them (75\%). Some publications contain multiple scripts about the same or different crime types. Those publications comprise a majority of peer-reviewed articles 
(49), followed by book chapters (14); theses (12); conference proceedings (6); and reports (4).

$<$ Add Figure 2 here $>$

Figure 3 indicates that 485 authors contributed to the 416 publications identified as being directly related to crime scripts. The great majority of the authors (75\%) have published just one article in this list; and only $22(5 \%)$ had (co-) authored five or more in that period. This suggests there are actually very few crime script experts or that they do not publish their scripts. It also shows the number of authors and the number of publications have increased in a similar fashion over time.

$<$ Add Figure 3 here $>$

\section{What types of crime have been scripted during that period?}

Not all the reviewed articles were focused on a particular crime type. For instance, Borrion (2013) wrote an article about quality assurance in crime scripting, and Leclerc (2013) discussed an extension of the script-theoretic approach to victims, without focusing on any particular crime type. Amongst the 416 reviewed studies, about three quarters could be associated to 157 specific crime types (Figure 4).

$<$ Add Figure 4 here $>$

Focusing on the 105 scripts identified in the search, we identified numerous crime types that could be classified into eight broad crime categories. Among them, 24 scripts were classified in two categories. The results in Tables 1 and 2 show the 
following categories are the most prevalent: cybercrime (24 scripts) and corruption and fraud offences (23), followed by robbery and theft offences (19), drugs offences (14), environmental crime (14), violent crime (13), sexual offences (9), and other (13).

$<$ Add Table 1 here $>$

$<$ Add Table 2 here $>$

That cybercrime tops this list can be attributed to the fact that it is a broad category that covers many crime types, including traditional crimes that have an online component (cyber-enabled crime). In addition, many academics in computer science departments conduct research to find defences against cyberattacks, which often starts with modelling them. The prevalence of cybercrime scripts can also be explained by the fact that data may be more readily available in this field where data transfers (e.g., financial transactions) are generally logged in computers and servers. It is noteworthy that fraud offenses also come very high in this list, as they often relate to trafficking in goods and counterfeits (e.g., alcohol, pharmaceutical and wildlife products) in various sectors.

\section{What methods have been used to generate, visualise and evaluate those scripts?}

Crime Script Generation

While this review found no study that describes in detail all the stages involved in generating, visualising, and evaluating crime scripts, it identified several publications containing information about those stages. 
Data sources: Sixty (71\%) of the 85 selected studies that include at least one original crime script, contain information about data sources used to generate the scripts. Eight publications indicated that their scripts had been created from primary data (Rege, 2012; Jacques \& Bernasco, 2013; Li, 2015). Twenty-nine scripts were created using a mix of primary and secondary data (e.g. Brayley, Cockbain \& Laycock, 2011) and twenty-three scripts were created using just secondary data (e.g. Meyer, 2011). Twenty five publications provided no or ambiguous information about the data used to create the scripts. In several cases, we found that authors had used the basic script structure available in a publication as a starting point, before using primary or secondary data to populate the script with details (e.g., Bright \& Delaney, 2013).

The secondary datasets reported in those publications were collected from both public and private sector organisations. They consist of court data (Chiu, Leclerc, \& Townsley, 2011); police reports (Brayley, Cockbain, \& Laycock, 2011) such as offenders' testimonies (Beauregard, Proulx, Rossmo, Leclerc, \& Allaire, 2007); interviews of experts and victims (Leukfeldt, 2014a; Willison, 2006b) ; police statistics (De Vries, 2012); surveys (Samonas, 2013; Willison, 2005); video footage (Borrion, Dehghanniri et al. 2017; Sytsma \& Piza, 2018), and synthesis of open data (Deslauriers-Varin \& Beauregard, 2010; Lavorgna, 2014a, 2014b; Meijerink, 2013).

Visualisation models: Three models have been used to represent the 105 identified crime scripts. The most prevalent models are tables with narratives (53\%) (e.g. Cornish 1994b), followed by flowcharts with narratives (37\%) (e.g. Cornish \& Clarke 2008), and text only (10\%) (e.g. Beauregard, Proulx, Rossmo, Leclerc, \& Allaire, 2007). Some publications that included tables with statistics about the attributes (e.g., space, time) of the crime commission process and the actors involved were not considered as crime scripts because they were not sufficient to understand the crime commission process. 
Borrion (2013) highlighted the importance of applying a formal verification or validation process to assess the quality of the generated crime scripts - see also (Dehghanniri \& Borrion, 2016; Hutchings \& Holt, 2015). To validate their script, Brayley, Cockbain, \& Laycock (2011) indicated they had used it as a 'stimulus for a structured brainstorming session' aimed at identifying interventions. However, idea generation was not constrained by specific practical considerations and the proposed interventions were not evaluated. Moreover, the lack of a comparison group (such as a group of analysts using no script or a low quality script) in their study means it is difficult to assess the extent to which the script influenced the outcomes of this process. Chiu, Leclerc, \& Townsley (2011) discussed about the degree of completeness of their script, indicating that the "gaps in [their] table reflect script stageintervention points for which the analysis was not able to reveal sufficient understanding for preventative measures'. They also pointed to some of the limitations caused by the fact that their sample was small and potentially not representative of the population of interest. The main aspect investigated in their study was the reliability of the initial data (data validity), a point also discussed in some other articles e.g., Basamanowicz \& Bouchard (2011); Beauregard \& Leclerc, (2007); Lantsman (2013), Le (2013), Lord, Spencer, Bellotti, \& Benson (2017), Sytsma \& Piza (2018), and Vakhitova \& Bell (2018).

\section{What other names are used for the term 'crime script'?}

More than 70 synonyms of the term 'crime script' were identified in the 416 reviewed publications. Those are often combinations of very similar synonyms for the words 'crime' and 'script'. As shown in Table 3, 'crime commission process' is the most common expression after 'crime script'. The first synonym that did not feature in 
Cornish's reference publication is 'scenario'. In this context, this term was found to be mostly used in the risk analysis and information security literature (e.g. Borrion \& Bouhana, 2012; Dimkov, 2012; Meyer \& Ekblom, 2012; Willison, 2006). This word could be used for the search stage in future reviews.

$<$ Add Table 3 here $>$

\section{Discussion}

\section{Twenty years after}

The results of this systematic review constitute the first evidence that the scripttheoretic approach has been gaining momentum within the research community, as affirmed by Leclerc (2017). Both the number of publications mentioning this approach and the pool of authors have increased exponentially, with $80 \%$ of those recorded in the last eight years of the studied period (1994-2018). It is noteworthy that the publications referring to this concept are not limited to a few specialist niches. On the contrary, they concern crime types across a wide spectrum, with the rather broad denomination of 'cybercrime' topping the list. Amongst those, the number of publications that contain at least one original crime script has been increasing in a similar fashion. These trends are encouraging for the dissemination and recognition of the script-theoretic approach, especially as they might reflect an increase in the creation and use of crime scripts by practitioners more widely. The magnitude of those figures is somewhat less impressive. With only 105 original crime scripts, the knowledge published in this area seems incredibly limited. 
There are reasons to believe, however, that the crime scripts identified in this systematic review may not be representative of the overall population of crime scripts:

- The scope of this systematic review was limited to those studies published after 1994, and using the words crime script(s) or citing Cornish's reference article. Because of this, only the work of those authors aware of Cornish's work at the time of writing was considered in this review. Publications that include procedural models of crime but make no direct mention of Cornish's concept would not have been included in our analysis.

- Because unpublished crime scripts were not taken into account, the total number of scripts generated in that period could be greater than our estimates by several orders of magnitude. Some scripts may have been created but considered too sensitive to be published (e.g., cases where intelligence reports are used as sources of information or where there is a risk that sharing procedural information helps offenders carry out those crimes).

- More extensive backward reference searching strategy (Levy \& Ellis, 2006; Tada, Kato, Asakawa, \& Azuma, 1998; Webster \& Watson, 2002) could have been used by searching through all the citations of the selected studies. However, this was not possible due to time constraints.

Taking all these points into account, it seems a reasonable conclusion that a lot more crime scripts might have been generated than those identified in this review, including some that describe crime types not unveiled here. Paradoxically, the quality of the scripts examined by the authors is likely to be unrepresentatively high since many of the identified publications are peer-reviewed articles. Given the lack of evidence in support of the quality of published scripts, one may therefore have doubts about that of unpublished scripts. To reiterate our findings, many of the published scripts have been authored by academics without evident track record of scripting crime: only $5 \%$ 
of the identified researchers have authored five or more of the identified publications in the studied period. Little comfort could be found in the reported methodology either: first, most identified scripts have been generated intuitively, without adhering to a strict and recognised scripting protocol; and second, there was not enough information available to replicate the work reported in those publications, assess the quality of the scripts, or ascertain the level of methodological rigour involved in their creation.

\section{Are existing crime scripting methods good enough?}

That published scripts are not accompanied by sufficient methodological details (i.e., data or specific information about the ways in which they were created) may have more to do with poor reporting than poor modelling. In fact, legitimate questions could be raised about the usefulness of formalising the crime scripting process. Indeed, the establishment of the script-theoretic approach can already be regarded as an unnecessarily complicated attempt to codify and systematise a practice that has been in existence long before being theorised by Cornish. Certainly, it is difficult to imagine how military engineers and security architects managed to create successful arrays of protective measures without framing problems using a script-based approach, and asking questions such as: What steps do most village attacks (burglaries) have in common? What can prevent marauders (burglars) from penetrating in villages (people's homes)? What would offenders do if defensive walls and watchtowers (fences and CCTV) were introduced around habitats? Etc.

If crime scripting is useful in finding innovative ways to prevent crime then surely it is worth investing time to think how best to generate, visualise and analyse crime scripts. Are intuitive ways to think about crime processes good enough? ...thereby implying that any past or future attempts to explain how to script crime are utterly futile. Perhaps one of the most useful findings emerging from the review is that we did not find enough 
evidence to answer this question. Simply put, there appears to have been no attempt to empirically assess the contribution of crime scripting techniques in the two decades that have followed the formalisation of the script-theoretic approach.

In this context, we can only highlight that more formal crime scripting methods have both advantages and disadvantages. Indeed, it can be hypothesized that providing more structured guidance helps communicating to junior crime analysts what the 'crime scripting' task entails. Greater methodological clarity should logically support their understanding of how to script crime, give them greater confidence in the resulting products, and increase their willingness to engage in problem-solving activities more generally rather than blindly opt for existing security recipes that may not be adapted to the problems of interest. Another possible advantage of using structured methods is that poor performance (i.e., inability to identify suitable crime reduction interventions) could be traced back to specific issues in the method that was prescribed or in the way it was applied, and subsequently addressed. Therefore, more structured methods (and possibly some form of standardisation) might be a necessary step to encourage greater integration and comparison of scripts.

However, opponents of structured methods are not without arguments. Indeed, the more detailed crime scripting methods, the more time and resources analysts have to invest in learning and applying them, which makes the script-theoretic approach less accessible and plays against its successful diffusion (Hardy, Thompson, \& Edwards, 1995; Yourdon, 1993). Although structured methods are intended to be generic (so they can be applied to many problems), there is always a possibility that they do not contain enough detail and scripters do not find them useful (Gillies, 2013; Hardy et al., 1995). This may be an issue here, as those methods do not always adapt well to different analytical needs. For instance, the level of specificity needed for the script may vary depending on the complexity of the crime, which could be difficult to 
communicate with a simple scripting method. Conversely, if the method is overly complicated, scripters may perceive the benefits are sufficiently high to invest time learning them, in comparison with in-house or intuitive methods (Hardy et al., 1995; Olle et al., 1992).

Without evidence that structured methods can yield substantial improvement, 'backof-the-envelop' scripting might therefore be considered good enough for most problems - even though they could actually offer substantial benefits in terms of crime reduction.

\section{Conclusions}

Cornish's vision for a script-theoretic approach to crime analysis is regarded as a methodological landmark in the analysis of crime and top-down rational development of crime reduction measures. Following this approach, analysis of individual crime commission procedures could unveil the factors and mechanisms giving rise to crime, and their comparison could reveal the flexibility, variation and evolution of crime activities. Following this approach, libraries of procedural models-not only effective modus operandi but also ineffective ones-would soon prove a formidable resource for identifying interventions. More than two decades later, the work of Cornish is still deeply relevant but his vision has yet to be fully delivered.

Searching for publications that contain the keyword 'crime script(s)' or citing Cornish's seminal article in the 1994-2018 period, our work has shown that the list of published crime scripts, whilst only representing a subset of all crime scripts, has grown exponentially since Cornish's seminal article. We noticed that scripts provide information about different aspects of the crime commission process. For example, there are studies that explain how some niche crimes happen in specialised industry 
sectors (e.g., waste crime). To non-specialists at least, the main information provided by those scripts is the basic procedural structure (i.e., the sequence of activities) of the studied crime. Other studies are concerned with crimes whose commission processes are simple and/or already known to criminologists (e.g., child abuse). For those, the contribution to knowledge in not the basic structure but in the variations in the crime commission process (e.g., alternative activities and relative frequencies), along with the details about the individual or environmental factors that influence it.

Characterised by breath rather than depth, the pool of crime scripts might reach a steady state once a script has been published for most crime types. At that point, a change of direction might be observed, with the generation and quantitative analysis of multiple and more detailed scripts (i.e., tracks) for each crime type. Borrion et al. (2019) also recommended creating scripts to study wider problems (e.g., breach of privacy, environmental harm, etc.). To accompany this development, it is likely that researchers will start adopting more systematic and transparent crime scripting methods. Already unsupervised algorithms exist that can automatically extra sequences of events from video footage. For such techniques to be adopted by crime analysts, convincing evidence will need to be produced about their added value.

Besides the lack of information about the quality of crime scripts, another important shortfall identified in this review is the lack of information about the usefulness of those scripts. Many authors have explained that their scripts were used to identiying crime prevention measures. There is, however, no study that empirically examines the usefulness of different existing scripting approaches. For this reason, we recommend to carry out experimental work to ascertain the added value of different crime scripting methods in comparison with others. 


\section{Acknowledgments}

We are very grateful to the anonymous reviewers and Prof. Ken Pease for their valuable comments. 


\section{References}

References marked with an asterisk $\left({ }^{*}\right)$ correspond to the publications reviewed in this work.

${ }^{*}$ Ashby, M. (2016). Using crime science for understanding and preventing theft of metal from the British railway network. PhD thesis. UCL (University College London).

* Baird, J., Curry, R., and Cruz, P. (2014). An overview of waste crime, its characteristics, and the vulnerability of the EU waste sector. Waste Management \& Research, 32(2), 97--105.

* Balemba, S. and Beauregard, E. (2013). Where and when? Examining spatiotemporal aspects of sexual assault events. Journal of sexual aggression, 19(2), 171-190.

* Basamanowicz, J. (2011). Release groups and digital copyright piracy. Arts \& Social Sciences: School of Criminology,

* Basamanowicz, J. and Bouchard, M. (2011). Overcoming the Warez paradox: online piracy groups and situational crime prevention. Policy \& Internet, 3(2), 1--25.

* Beauregard, E. and Leclerc, B. (2007). An application of the rational choice approach to the offending process of sex offenders: A closer look at the decision-making. Sexual Abuse: A Journal of Research and Treatment, 19(2), 115-133.

* Beauregard, E. and Martineau, M. (2015). An application of CRAVED to the choice of victim in sexual homicide: a routine activity approach. Crime Science, 4(1), 111.

* Beauregard, E., Proulx, J., Rossmo, K., Leclerc, B. and Allaire, J.-F. (2007). Script analysis of the hunting process of serial sex offenders. Criminal Justice and Behavior, 34(8), 1069-1084.

* Beauregard, E., Rossmo, D. K. and Proulx, J. (2007). A descriptive model of the hunting process of serial sex offenders: A rational choice perspective. Journal of Family Violence, 22(6), 449-463.

Bennett, M. (1993). The Child as Psychologist: An introduction to the development of social cognition. New York: Harvester Wheatsheaf.

Bernasco, W. (2010). A sentimental journey to crime: Effects of residential history on crime location choice. Criminology, 48(2), 389-416.

* Bichler, G., Bush, S. and Malm, A. (2013). Bad actors and faulty props: unlocking legal and illicit art trade. Global Crime, 14(4), 359-385.

* Bichler, G., Bush, S. and Malm, A. (2015). Regulatory Foresight Estimating Policy Effects on Transnational Illicit Markets. Journal of Contemporary Criminal Justice, 1043986215575138.

* Block, S. (2012). An analysis of internationally exported vehicle thefts in two highrisk cities. Rutgers University-Graduate School-Newark, 
Boeker, M., Vach, W. and Motschall, E. (2013). Google Scholar as replacement for systematic literature searches: good relative recall and precision are not enough. BMC medical research methodology, 13(1), 131.

* Borrion, H. (2013). Quality assurance in crime scripting. Crime Science, 2(1), 6.

* Borrion, H. and Bouhana, N. (2012). iCARE: A Scenario-Based Method for the RIBS Project. In: 2012 European Intelligence and Security Informatics Conference (EISIC), 2012.

Borrion, H. Ekblom, P., Alrajeh, D. Borrion, A., Keane, A., Koch, D., Mitchener-Nissen, T. \& Toubaline S. (2019) The Problem with Crime Problem-Solving: Towards a Second Generation POP? British Journal of Criminology.

* Borrion, H., Dehghanniri, H. and Li Y. (2017). Comparative Analysis of Crime Scripts: One CCTV Footage-Twenty-One Scripts. In: 2017 European Intelligence and Security Informatics Conference (EISIC), 115-122, IEEE.

Bowers, K., Johnson, S., Guerette, R. T., Summers, L. and Poynton, S. (2010). Systematic Review of the Empirical Evidence of Spatial Displacement and Diffusion of Benefit among Geographically Focused Policing Initiatives. Report submitted to the Center for Evidence Based Crime Policy at George Mason University and the National Policing Improvement Agency (UK).

Bowers, K. J., Johnson, S. D., Guerette, R. T., Summers, L. and Poynton, S. (2011). Spatial displacement and diffusion of benefits among geographically focused policing initiatives: a meta-analytical review. Journal of Experimental Criminology, 7(4), 347-374.

* Brayley, H., Cockbain, E. and Laycock, G. (2011). The value of crime scripting: deconstructing internal child sex trafficking. Policing, 5(2), 132-143.

* Bright, D. A. and Delaney, J. J. (2013). Evolution of a drug trafficking network: Mapping changes in network structure and function across time. Global Crime, 14(2-3), 238-260.

Brookman, F., Bennett, T., Hochstetler, A. and Copes, H. (2011). The 'Code of the Street' and the Generation of Street Violence in the UK. European Journal of Criminology, 8(1), 17-31.

* Bullock, K., Clarke, R. V. G. and Tilley, N. (2010). Situational prevention of organised crimes. Cullompton: Willan Publishing.

* Caneppele, S., Riccardi, M. and Standridge, P. (2013). Green energy and black economy: mafia investments in the wind power sector in Italy. Crime, law and social change, 59(3), 319-339.

* Chiu, Y. N., Leclerc, B. and Townsley, M. (2011). Crime script analysis of drug manufacturing in clandestine laboratories: Implications for Prevention. British Journal of Criminology, 51(2), 355-374. doi:10.1093/bjc/azr005

Clarke, R. (1997). Situational Crime Prevention: Successful Case Studies. New York: Harrow and Heston: ISBN 0-911577-39-4.

* Clarke, R. (2009). Situational crime prevention: Theoretical background and current practice. In Handbook on crime and deviance. New York, NY: Springer, 259276.

* Clarke, R. and Eck, J. E. (2003). Become a problem-solving crime analyst. London : Jill Dando Institute of Crime Science: 2003. 
Claus, V., Ehrig, H. and Rozenberg, G. (1979). Graph-grammars and their application to computer science and biology. International workshop, Bad Honnef, October 30-November 3, 1978, (1): Springer Science \& Business Media.

* Cook, A., Reynald, D. M., Leclerc, B. and Wortley, R. (2018). Learning About Situational Crime Prevention From Offenders: Using a Script Framework to Compare the Commission of Completed and Disrupted Sexual Offenses. Criminal Justice Review, 0734016818812149.

Cornish, D. B. (1994a). Crimes as scripts. In Proceedings of the international seminar on environmental criminology and crime analysis.

* Cornish, D. B. (1994b). The procedural analysis of offending and its relevance for situational prevention. Crime prevention studies, 3, 151-196.

* Cornish, D. B. and Clarke, R. V. (2002). Analyzing organized crimes. In: Piquero A. R. and Tibbetts S. G. (eds) Rational choice and criminal behavior: Recent research and future challenges. London: Routledge, 41-62

* Cornish, D. B. and Clarke, R. V. (2003). Opportunities, precipitators and criminal decisions: A reply to Wortley's critique of situational crime prevention. Crime prevention studies, 16, 41-96.

* Cornish, D. B. and Clarke, R. V. (2008). The rational choice perspective. Environmental criminology and crime analysis, 21-47.

* Dalla Gasperina, G. (2014). Illegal waste Traffic and legitimate Market Players: legislative Opportunities in Italy. PhD Thesis. University of Trento,

* De Bie, J. L., De Poot, C. J. and Van Der Leun, J. P. (2015). Shifting Modus Operandi of Jihadist Foreign Fighters From the Netherlands Between 2000 and 2013: A Crime Script Analysis. Terrorism and Political Violence, 1-25.

* De Vries, M. S. (2012). Converted firearms: a transnational problem with local harm. European Journal on Criminal Policy and Research, 18(2), 205-216.

* De Vries, M. S. (2013). From the instrument of delivery to the actual agent of harm: fighting the criminal purchase of ammunition. European Journal on Criminal Policy and Research, 19(1), 1-14.

* Dehghanniri, H. and Borrion, H. (2016). Toward a More Structured Crime Scripting Method. In: Requirements Engineering Conference Workshops (REW), IEEE International.

* Dehghanniri, H., Letier, E. and Borrion, H. (2015). Improving security decision under uncertainty: A multidisciplinary approach. In: Cyber Situational Awareness, Data Analytics and Assessment (CyberSA), International Conference on. London.

* Deslauriers-Varin, N. and Beauregard, E. (2010). Victims routine activities and sex offenders target selection scripts: A latent class analysis. Sexual Abuse: A Journal of Research and Treatment, 22(3), 315-342.

* Dimkov, T. (2012). Alignment of organizational security policies: theory and practice. University of Twente.

* Dimkov, T., Van Cleeff, A., Pieters, W. and Hartel, P. (2010). Two methodologies for physical penetration testing using social engineering. In Proceedings of the 26th annual computer security applications conference.

* Duijn, P. and Sloot, P. (2015). From data to disruption. Digital Investigation, 15, 3945.

* Duijn, P. A., Kashirin, V. and Sloot, P. M. (2014). The relative ineffectiveness of criminal network disruption. Scientific reports, 4. 
* Duijn, P. A. and Klerks, P. P. (2014). Social network analysis applied to criminal networks: Recent developments in dutch law enforcement. In Masys A.J. (ed). Networks and Network Analysis for Defence and Security (pp. 121--159): Springer.

* Ekblom, P. and Gill, M. (2016). Rewriting the Script: Cross-Disciplinary Exploration and Conceptual Consolidation of the Procedural Analysis of Crime. European Journal on Criminal Policy and Research, 1-21.

*Ekblom, P. and Sidebottom, A. (2008). What do you mean,'Is it secure?' Redesigning language to be fit for the task of assessing the security of domestic and personal electronic goods. European Journal on Criminal Policy and Research, 14(1), 61$-87$.

* Gamman, L., Thorpe, A., Malpass, M. and Liparova, E. (2012). Hey Babe Take a Walk on the Wild Side! Why Role-playing and Visualization of User and Abuser Scripts Offer Useful Tools to Effectively Think Thief and Build Empathy to Design Against Crime. Design and Culture, 4(2), 171-193.

* Gentry, K. (2015). Apple Picking: The Rise of Electronic Device Thefts in Boston Subways. Newton, A and Ceccato, V, (eds.) Safety and Security in Transit Environments: An Interdisciplinary Approach. London, UK. (2015): Palgrave Macmillan. 39.

* Gilliam Jr, F. D. and lyengar, S. (2000). Prime suspects: The influence of local television news on the viewing public. American Journal of Political Science, 560-573.

Gillies, P. S. A. C. (2013). Managing software engineering: CASE studies and solutions: Springer.

* Gilmour, N. (2014). Understanding Money Laundering - A Crime Script Approach. European Review of Organized Crime, 1(2), 35--56.

* Gilmour, N. (2015). Understanding the practices behind money laundering--A rational choice interpretation. International Journal of Criminal Law, Crime and Justice. 4, 1-13.

Goldstein, H. (1979). Improving policing: A problem-oriented approach. Crime \& delinquency, 25(2), 236-258.

Gough, D., Oliver, S. and Thomas, J. (2012). An introduction to systematic reviews: Los Angeles: Sage.

* Haelterman, H. (2016). Scripting Crime Against Business. In Crime Script Analysis: London: Palgrave Macmillan. 113-159.

Hagan, J. and Levi, R. (2004). Social skill, the Milosevic indictment, and the rebirth of international criminal justice. European Journal of Criminology, 1(4), 445-475.

Hardy, C. J., Thompson, J. B. and Edwards, H. M. (1995). The use, limitations and customization of structured systems development methods in the United Kingdom. Information and Software Technology, 37(9), 467-477.

* Hartel, P.H., Junger, M., Wieringa, R.J.: Cyber-crime Science = Crime Science + Information Security. Technical Report TR-CTIT-10-34, CTIT, University of Twente, Oct 2010. http://eprints.eemcs.utwente.nl/18500/

Henley, E. J. and Kumamoto, H. (1981). Probabilistic risk assessment: reliability engineering, design, and analysis: IEEE.

* Hill, J. F. (2015). A Systems Thinking Perspective on the Motivations and Mechanisms That Drive Wildlife Poaching. In Sollund R.A. (ed), Green Harms and 
Crimes: Critical Criminology in a Changing World, London: Palgrave Macmillan. 189219.

* Hiropoulos, A., Freilich, J. D., Chermak, S. and Newman, G. R. (2013). 10 Cigarette smuggling and terrorism financing. In Leclerc B. and Wortley R. (eds). Cognition and Crime: Offender Decision Making and Script Analyses. Routledge. 186.

Hobbs, D., Winlow, S., Hadfield, P. and Lister, S. (2005). Violent hypocrisy: Governance and the night-time economy. European journal of criminology, 2(2), 161-183.

Holton, J. A. (2007). The coding process and its challenges. The Sage handbook of grounded theory (Part III), 265-289.

* Hopkins, M. and Chivers, S. (2018). Understanding and preventing hit-and-run driving: a crime script analysis. Crime prevention and community safety, 20(1), 16-29.

* Hutchings, A. (2018). Leaving on a jet plane: the trade in fraudulently obtained airline tickets. Crime, Law and Social Change, 70(4), 461-487.

* Hutchings, A. and Holt, T. J. (2015). A Crime Script Analysis of the Online Stolen Data Market. British Journal of Criminology, 55(3), 596-614.

* Jacques, S. and Bernasco, W. (2013). Drug dealing. In Leclerc B. and Wortley R. Cognition and Crime: Offender Decision Making and Script Analyses. Routledge. 120.

Johnson, S., Tilley, N. and Bowers, K. (2015). Introducing EMMIE: An evidence rating scale to encourage mixed-method crime prevention synthesis reviews. Journal of Experimental Criminology, 11(3), 459-473.

Johnson, S. D., Bowers, K. and Hirschfield, A. (1997). New insights into the spatial and temporal distribution of repeat victimization. The British Journal of Criminology, 224-241.

Keele, S. (2007). Guidelines for performing systematic literature reviews in software engineering. In Technical report, Ver. 2.3 EBSE Technical Report. EBSE.

* Kennedy, J. P., Haberman, C. P. and Wilson, J. M. (2018). Occupational pharmaceutical counterfeiting schemes: A crime scripts analysis. Victims \& Offenders, 13(2), 196-214.

* Knapik, P., Schoch, E., Muller, M. and Kargl, F. (2012). Understanding vehicle related crime to elaborate on countermeasures based on ADAS and V2X communication. In Vehicular Networking Conference (VNC), 2012 IEEE.

* Lantsman, L. (2013). "Moveable currency": the role of seaports in export oriented vehicle theft. Crime, Law and Social Change, 59(2), 157-184.

* Lasky, N., Jacques, S. and Fisher, B. S. (2015). Glossing Over Shoplifting: How Thieves Act Normal. Deviant Behavior, 36(4), 293-309.

* Lavorgna, A. (2013). Scripting OC in the eSociety: identifying a new structure of online criminal opportunities for offline transit crimes. In European Consortium for Political Research, European General Conference. September 2013.

* Lavorgna, A. (2014a). Internet-mediated drug trafficking: towards a better understanding of new criminal dynamics. Trends in Organized Crime, 17(4), 250-270.

* Lavorgna, A. (2014b). Transit crimes in the Internet age: How new online criminal opportunities affect the organization of offline transit crimes. Thesis: University of Trento. 
* Lavorgna, A. (2014c). Wildlife trafficking in the Internet age. Crime Science, 3(1), 112.

Lavorgna, A. (2015). The online trade in counterfeit pharmaceuticals: new criminal opportunities, trends and challenges. European Journal of Criminology, 12(2), 226-241.

* Le, V. K. T. (2013). Understanding the operational structure of Southeast Asian drug trafficking groups in Australia. Queensland University of Technology.

* Leberatto, A. C. (2015). Survivor scripts and safety scripts in Lima, Peru: citizens' cognitive assessments and decisions to maintain safety during victimization events and in their daily routines. Rutgers University-Graduate School-Newark,

* Leclerc, B. (2013). New developments in script analysis for situational crime prevention. In Leclerc B. and Wortley R. (eds). Cognition and Crime: Offender Decision Making and Script Analyses. Routledge. 221.

* Leclerc, B. (2014). Script Analysis for Crime Controllers: Extending the Reach of Situational Crime Prevention. In Caneppele S. and Calderoni F. Organized Crime, Corruption and Crime Prevention: Springer. 13-20.

* Leclerc, B. (2017). Script Analysis and the SCRIPT Acronym. In Leclerc B. and Savona E.U. (eds). Crime Prevention in the 21st Century. Springer. 49-58.

* Leclerc, B. and Reynald, D. (2015). When scripts and guardianship unite: A script model to facilitate intervention of capable guardians in public settings. Security Journal.

* Leclerc, B. and Wortley, R. (2013). Cognition and Crime: Offender Decision Making and Script Analyses. Routledge.

* Leclerc, B., Wortley, R. and Smallbone, S. (2011). Getting into the script of adult child sex offenders and mapping out situational prevention measures. Journal of research in crime and delinquency, 0022427810391540.

Leenders, R. T. A., Van Engelen, J. M. and Kratzer, J. (2007). Systematic design methods and the creative performance of new product teams: Do they contradict or complement each other? Journal of Product Innovation Management, 24(2), 166-179.

* Leontiadis, N. (2014). Structuring disincentives for online criminals. Carnegie Mellon University Pittsburgh, PA,

* Leontiadis, N. and Hutchings, A. (2015). Scripting the crime commission process in the illicit online prescription drug trade. Journal of Cybersecurity, 1(1), 81-92.

* Leukfeldt, E. (2014). Cybercrime and social ties. Trends in Organized Crime, 17(4), 231--249.

* Leukfeldt, R. and Jansen, J. (2015). Cyber Criminal Networks and Money Mules: An Analysis of Low-Tech and High-Tech Fraud Attacks in the Netherlands. International Journal of Cyber Criminology, 9(2), 173.

* Levi, M. (2008). Organized fraud and organizing frauds Unpacking research on networks and organization. Criminology and Criminal Justice, 8(4), 389--419.

Levy, Y. and Ellis, T. J. (2006). A systems approach to conduct an effective literature review in support of information systems research. Informing Science: International Journal of an Emerging Transdiscipline, 9(1), 181-212.

* Li, J. C. (2015). Adolescent Compensated Dating in Hong Kong Choice, Script, and Dynamics. International journal of offender therapy and comparative criminology, 59(6), 588-610. 
Lord, $\mathrm{N}$ and Levi, M. (2017). Organizing the finances for and the finances from transnational corporate bribery. European Journal of Criminology, 14(3), 365389.

Lord, N., Spencer, J., Bellotti, E. and Benson, K. (2017). A script analysis of the distribution of counterfeit alcohol across two European jurisdictions. Trends in Organized Crime, 1-21.

* Meijerink, T. J. (2013). Carding: crime prevention analysis.

* Meyer, S. (2011). Preventing mass killings: optimal strategies for protecting public targets against terrorist attacks. PhD Thesis: University of Oslo.

* Meyer, S. (2012). Reducing harm from explosive attacks against railways. Security Journal, 25(4), 309-325.

* Meyer, S. (2013). Impeding lone-wolf attacks: lessons derived from the 2011 Norway attacks. Crime Science, 2(1), 1--13.

* Meyer, S. and Ekblom, P. (2012). Specifying the explosion-resistant railway carriage-a 'bench'test of the Security Function Framework. Journal of Transportation Security, 5(1), 69-85.

* Meyer, S., Jore, S. H. and Johansen, K. W. (2015). Troublesome trade-offs: balancing urban activities and values when securing a city-centre governmental quarter. City, Territory and Architecture, 2(1), 1--15.

* Moreto, W. D. and Lemieux, A. (2014). From CRAVED to CAPTURED: Introducing a Product-Based Framework to Examine Illegal Wildlife Markets. European Journal on Criminal Policy and Research, 1-18.

* Morselli, C. and Roy, J. (2008). Brokerage qualifications in ringing operations. Criminology, 46(1), 71--98.

* Olle, TW. , Hagelstein J., Macdonald, G., Rollands, C., Sol, H. G., Van Assche F. J. M. and Verrijn-Stuart, A. A. (1992). Information Systems Methodologies: A Framework for Understanding. Journal of the Operational Research Society, 43(3), 286-286.

ONS. (2015). User Guide to Crime Statistics for England and Wales, Office for National Statistics. Retrieved from http://www.ons.gov.uk/ons/guidemethod/method-quality/specific/crime-statistics-methodology/user-guide-tocrime-statistics.pdf

* Osborne, J. R. and Joel A. C. (2017). Examining active shooter events through the rational choice perspective and crime script analysis. Security journal 30.3, 880902.

Pease, K. (1998). Repeat victimisation: Taking stock (Vol. 90): Home Office Police Research Group London.

* Price, V., Sidebottom, A. and Tilley, N. (2014). Understanding and Preventing Lead Theft from Churches: A Script Analysis. In Grove L. and Thomas S. (eds). Heritage Crime: Progress, Prospects and Prevention. London: Palgrave Macmillan. 128.

* Rege, A. (2012). Cybercrimes against the electricity infrastructure: exploring hacker and industry perceptions. Rutgers University-Graduate School-Newark,

* Rowe, E., Akman, T., Smith, R. G. and Tomison, A. M. (2012). Organised crime and public sector corruption: a crime scripts analysis of tactical displacement risks. Trends and Issues in Crime and Criminal Justice (444), 1. 
* Samonas, S. (2013). Insider fraud and routine activity theory. In 12th Annual Security Conference.

* Savona, E., Giommoni, L. and Mancuso, M. (2014). Human trafficking for sexual exploitation in Italy. In Leclerc B. and Wortley R. (eds). Cognition and Crime: Offender Decision Making and Script Analyses. Routledge. 140-163.

Sidebottom, A., Tompson, L., Thornton, A., Bullock, K., Tilley, N., Bowers, K., . . . Sidebottom, A. (2015). What works: crime reduction systematic review series.

* Smith, M. J. (2008). Addressing the security needs of women passengers on public transport. Security Journal, 21(1), 117--133.

* Smith, M. J. (2009). A six-step model of potential victims' decisions to change location, Security Journal, 22(3), 230-249.

* Smith, M. J. (2014). Civil Remedies. Encyclopedia of Criminology and Criminal Justice, 338-353.

* Smith, M. J. and Clarke, R. V. (2000). Crime and public transport. Crime and Justice, 27, 169-233.

Snook, B., Eastwood, J., Gendreau, P., Goggin, C. and Cullen, R. M. (2007). Taking stock of criminal profiling: A narrative review and meta-analysis. Criminal Justice and Behavior. 34(4), 437-453

* Soudijn, M. R. and Zegers, B. C. T. (2012). Cybercrime and virtual offender convergence settings. Trends in Organized Crime, 15(2-3), 111--129.

* Sytsma, V. A. and Piza, E. L. (2018). Script Analysis of Open-air Drug Selling: A Systematic Social Observation of CCTV Footage. Journal of Research in Crime and Delinquency, 55(1), 78-102.

Tada, K., Kato, K., Asakawa, S. and Azuma, A. (1998). Document searching method using forward and backward citation tables. In: Google Patents.

* Tompson, L. and Chainey, S. (2011). Profiling illegal waste activity: using crime scripts as a data collection and analytical strategy. European Journal on Criminal Policy and Research, 17(3), 179--201.

* Tremblay, P., Talon, B. and Hurley, D. (2001). Body switching and related adaptations in the resale of stolen vehicles. Script elaborations and aggregate crime learning curves. British Journal of Criminology, 41(4), 561--579.

*Vakhitova, Z. I. and Bell, P. J. (2018). A script analysis of the role of athletes' support networks as social facilitators in doping in sport. Crime Prevention and Community Safety, 20(3), 168-188.

* van Doormaal, N., Lemieux, A. M. and Ruiter, S. (2018). Understanding site selection of illegal border crossings into a fenced protected area: a rational choice approach. Crime Science, 7(1), 7.

* van Hardeveld, G. J., Webber, C. and O'Hara, K. (2016). Discovering credit card fraud methods in online tutorials. In Proceedings of the 1st International Workshop on Online Safety, Trust and Fraud Prevention.

* Viollaz, J., Graham, J. and Lantsman, L. (2018). Using script analysis to understand the financial crimes involved in wildlife trafficking. Crime, Law and Social Change, 69(5), 595-614.

Webster, J. and Watson, R. T. (2002). Analyzing the past to prepare for the future: Writing a literature review. In (pp. xiii-xxiii): JSTOR. 
* Wilkinson, D. (2011). An Emergent Situational and Transactional Theory of Urban Youth Violence. In Bishop, D. and Feld, B. C. The Oxford Handbook of Juvenile Crime and Juvenile Justice. Cambridge: Oxford University Press.

* Willison, R. (2005). Considering the Offender: Addressing the Procedural Stages of Computer Crime in an Organisational Context. København.

* Willison, R. (2006). Understanding the perpetration of employee computer crime in the organisational context. Information and organization, 16(4), 304--324.

* Willison, R. (2008). Applying Situational Crime Prevention to the Information Systems Security Context. In McNally M. M. and Newman G. R. (eds), Perspectives on Identity Theft. 151-167

* Willison, R. and Siponen, M. (2006). Overcoming the insider: reducing employee computer crime through Situational Crime Prevention. Communications of the ACM, 52(9), 133-137.

* Wortley, R. and Mazerolle, L. (2013). Situating the theory, analytic approach and application. Environmental criminology and crime analysis. Willan. 1-18.

Wright, R. W., Brand, R. A., Dunn, W. and Spindler, K. P. (2007). How to write a systematic review. Clinical orthopaedics and related research, 455, 23-29.

Yourdon, I. (1993). Yourdon systems method: model-driven systems development: Prentice Hall.

* Yun, M. and Roth, M. (2008). Terrorist hostage-taking and kidnapping: Using script theory to predict the fate of a hostage. Studies in Conflict \& Terrorism, 31(8), 736-748.

* Zanella, M. (2013). Script analysis of corruption in public procurement. In Leclerc B. and Wortley R. (eds). Cognition and Crime: Offender Decision Making and Script Analyses. Routledge. 164. 
Figure 1. Stages of the screening process

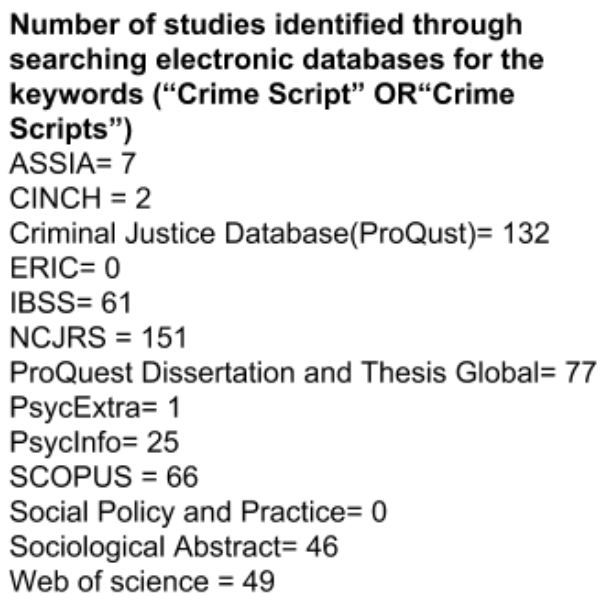

Number of studies identified through searching other data sources for the keywords ("Crime Script" OR"Crime Scripts")

Link.springer $=134$

Oxford Journals $=23$

Wiley Online Library $=15$

Number of studies identified through searching studies that cited (Cornish, $1994 b)=424$
Number of identified studies $=889$

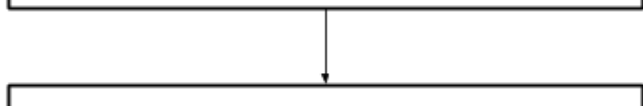

Number of studies in English $=815$

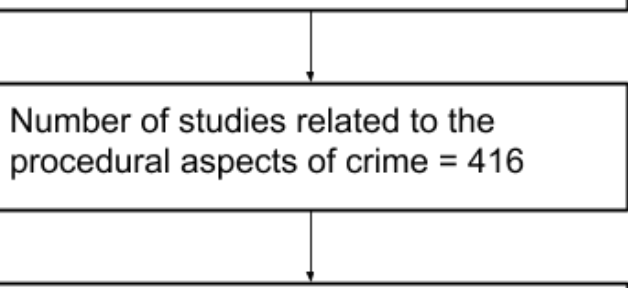

Number of studies that contain a crime script $=114$ (85 contain an original one)

Number of studies that contain some information about crime script assessment $=8$

Figure 2. Cumulative frequency distribution showing the number of publications mentioning the script-theoretic approach (dark grey) or including an original crime script (light grey), over time (1994-2018)

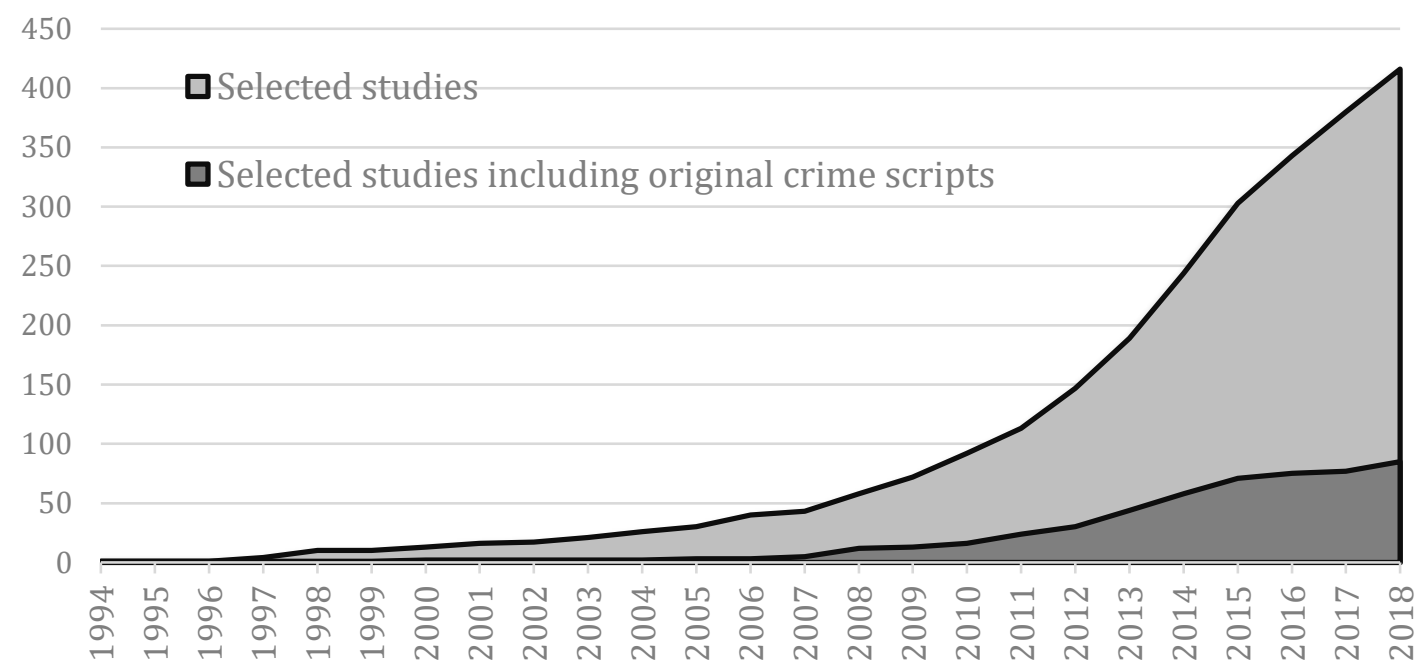


Figure 3. Cumulative frequency distribution showing the number of authors of publications mentioning the script-theoretic approach (dark grey) or including an original crime script (light grey), over time (1994-2018)

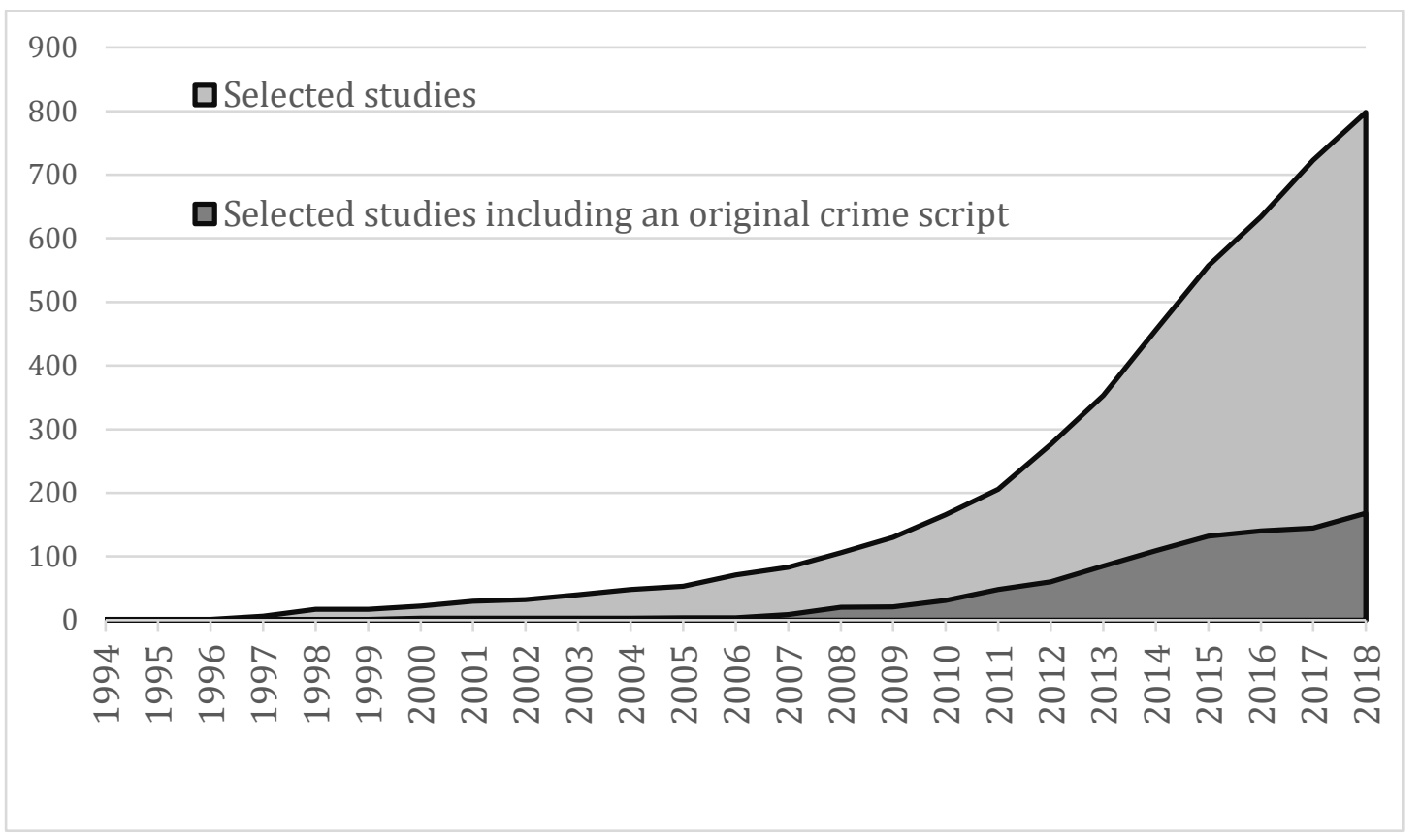

Figure 4. Crime types discussed in the selected studies

transport cyber physical incidents social network public safety white collar crime counterfeit alcohol distribution illegal waste activity - sexual crime crime in public transport compensated dating

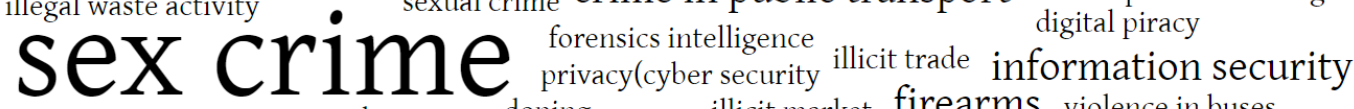
auto burglary computer abuse doping illicit market firearms violence in buses kidnapping complex crime drug trafficking violent crime hit and run credit card fraud fraud terrorist hostage sexual offence violent youth

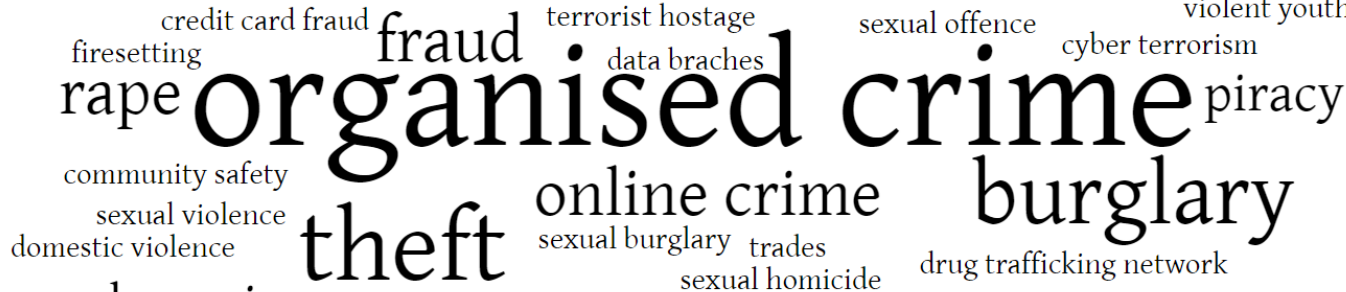

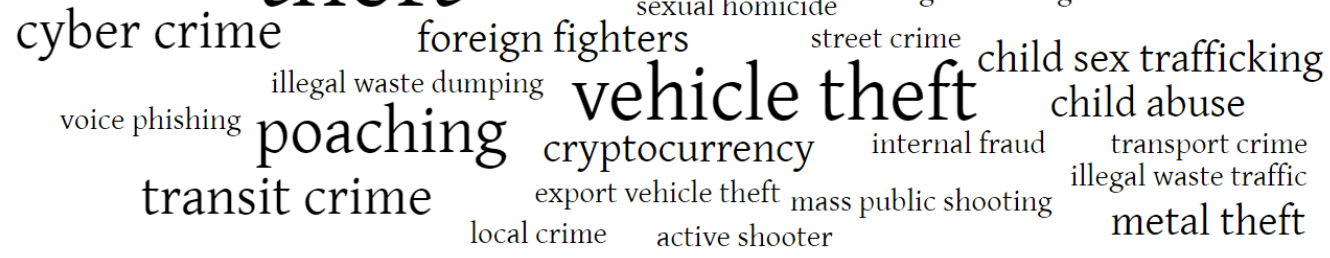

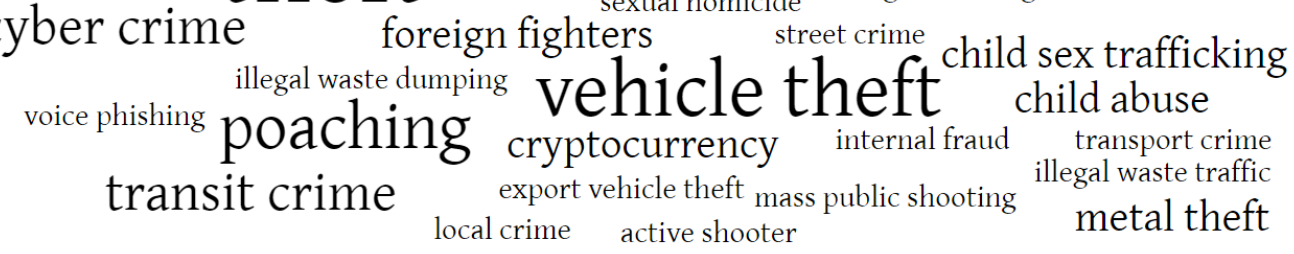


Table 1. Number of scripts per crime category (1994-2018)

\begin{tabular}{|l|c|}
\hline Crime type & $\begin{array}{c}\text { Number of original } \\
\text { crime scripts }\end{array}$ \\
\hline Cybercrime & 24 \\
\hline Corruption and fraud offences & 23 \\
\hline Robbery and theft offences & 19 \\
\hline Drugs offences & 14 \\
\hline Environmental crime & 13 \\
\hline Violent crime & 13 \\
\hline Sexual offences & 9 \\
\hline Other & 13 \\
\hline
\end{tabular}

Some of the identified crime scripts were mapped to multiple crime types. For example, the Process of Seafood Substitution, Short Weighting, Mislabeling and Overtreatment of Seafood Upon

Landing is related to both Environmental crime and Corruption and fraud offences 
Table 2. Crime types covered by the 105 crime scripts (1994-2018)

\begin{tabular}{|c|c|}
\hline Cybercrime & $\begin{array}{l}\text { Account takeover (Haelterman, 2016; Willison, 2005); Attacks on online banking } \\
\text { (Leukfeldt \& Jansen, 2015); Carding (Meijerink, 2013); Cybercrime against electricity } \\
\text { infrastructure (Rege, 2012); Internet-related criminal opportunities (Lavorgna, 2014b); } \\
\text { Mapping trolling on a cyber attack journey (Somer, Tiido, Sample, \& Mitchener- } \\
\text { Nissen, 2018); Phishing (Leukfeldt, 2014); Physical penetration (Dimkov, Van Cleeff, } \\
\text { Pieters, \& Hartel, 2010); (Illegal/Warez) release process (Basamanowicz, 2011; } \\
\text { Basamanowicz \& Bouchard, 2011) }\end{array}$ \\
\hline $\begin{array}{l}\text { Corruption and } \\
\text { Fraud offences }\end{array}$ & $\begin{array}{l}\text { Cigarette smuggling (Hiropoulos, Freilich, Chermak, \& Newman, 2013); Corruption } \\
\text { (Rowe, Akman, Smith, \& Tomison, 2012); Corruption in public procurement of works } \\
\text { contracts (Zanella, 2013); Counterfeit alcohol distribution (Lord, Spencer, Bellotti, \& } \\
\text { Benson, 2017a); Credit card fraud (van Hardeveld, Webber, \& O'Hara, 2016); Credit } \\
\text { card identity theft (Dehghanniri, Letier \& Borrion, 2015); Expense reimbursement } \\
\text { fraud (Haelterman, 2016); (Fraudulent) ticket purchase (Hutchings, 2018); Internet- } \\
\text { mediated trade in counterfeit pharmaceuticals (Lavorgna, 2014b); Money laundering } \\
\text { (Gilmour, 2014); Online auction fraud (Hartel, Junger, \& Wieringa, 2010); } \\
\text { Pharmaceutical counterfeiting (Kennedy, Haberman, \& Wilson, 2018); The process of } \\
\text { fraud and other crimes for gain (Levi, 2008); Stolen card fraud (Haelterman, 2016). }\end{array}$ \\
\hline $\begin{array}{l}\text { Robbery and } \\
\text { Theft offences }\end{array}$ & $\begin{array}{l}\text { Armed robbery (Borrion et al., 2017; Leclerc \& Wortley, 2013); Auto-theft (Cornish, } \\
\text { 1994); Car theft (Knapik, Schoch, Muller, \& Kargl, 2012); Metal theft from railway } \\
\text { (Ashby, 2016); Pickpocketing (Gentry, 2015); Professional auto theft (Cornish \& } \\
\text { Clarke, 2002); Ringing script (Morselli \& Roy, 2008); Robbery (Gentry, 2015); } \\
\text { Shoplifting (Lasky et al., 2015); Snatch theft (Gentry, 2015); Stolen vehicle pathway } \\
\text { (Lantsman, 2013); Suburban burglary (Cornish \& Clarke, 2008); Subway mugging } \\
\text { (Cornish, 1994); Taxi robbery (Smith \& Clarke, 2000); Theft from a moving vehicle } \\
\text { (Haelterman, 2016); Theft from churches (Price, Sidebottom, \& Tilley, 2014) ; Theft of } \\
\text { electronic products (Ekblom \& Sidebottom, 2008); Vehicle theft (Block, 2012; Morselli } \\
\text { \& Roy, 2008) }\end{array}$ \\
\hline $\begin{array}{l}\text { Sexual } \\
\text { offences }\end{array}$ & $\begin{array}{l}\text { Child sex abuse (Leclerc, Wortley, \& Smallbone, 2011, 2013); Child sex trafficking } \\
\text { (Brayley, Cockbain, \& Laycock, 2011); Compensated dating (Li, 2015); Human } \\
\text { trafficking (Savona, Giommoni, \& Mancuso, 2014); Internet-mediated sex trafficking } \\
\text { (Lavorgna, 2014b); Offending process of sex offenders (Beauregard \& Leclerc, 2007); } \\
\text { Sexual assault (Beauregard \& Leclerc, 2007); Sexual offences (Cook, Reynald, } \\
\text { Leclerc, \& Wortley, 2018); The tracking of stranger-perpetrator in public places } \\
\text { (Beauregard, Rossmo, \& Proulx, 2007). }\end{array}$ \\
\hline Violent crime & $\begin{array}{l}\text { Crime script for active shooter event (Osborne \& Capellan, 2015); Explosive in rail } \\
\text { carriage (Meyer, 2011); Foreign fighting (De Bie, De Poot, \& Van Der Leun, 2015); } \\
\text { Hit-and-run (Hopkins \& Chivers, 2018); Hostage taking (Yun \& Roth, 2008); Illegal } \\
\text { trade in ammunition (De Vries, 2013); Mass shooting (Meyer, 2013); Trade and use of } \\
\text { converted firearms (De Vries, 2012); Urban youth violence events (Wilkinson, 2011); } \\
\text { Vehicle-borne explosives (Meyer, 2012); Violent crime (Smith, 2008, 2009). }\end{array}$ \\
\hline $\begin{array}{l}\text { Drugs } \\
\text { offences }\end{array}$ & $\begin{array}{l}\text { Cannabis cultivation (Duijn, Kashirin, \& Sloot, 2014; Duijn \& Klerks, 2014); } \\
\text { Clandestine Drug laboratories-drug manufacturing (Chiu, Leclerc, \& Townsley } \\
2011 \text { ); Domestic methamphetamine supply chain (Bright \& Delaney, 2013); Drug } \\
\text { dealing (Jacques \& Bernasco, 2013); Heroin production, importation, and distribution } \\
\text { (Le, 2013); Internet-mediated trafficking in synthetic drugs and NPSs (Lavorgna, } \\
\text { 2014b); Internet-mediated trafficking in traditional recreational drugs (Lavorgna, } \\
\text { 2014b); Online drug trade (Leontiadis \& Hutchings, 2015); Open-air drug selling } \\
\text { (Sytsma \& Piza, 2018). }\end{array}$ \\
\hline $\begin{array}{l}\text { Environmental } \\
\text { crime }\end{array}$ & $\begin{array}{l}\text { Illegal ivory market (Moreto \& Lemieux, 2014); Illegal waste dumping (Sahramäki \& } \\
\text { Kankaanranta, 2017); Illegal waste traffic (Dalla Gasperina, 2014); Illegal hunting, } \\
\text { poaching, and illegal wildlife trade (Hill, 2015); Internet-mediated wildlife trafficking } \\
\text { (Lavorgna, 2014b); Process of removal and transshipment and landing of illegal, } \\
\text { unreported, and unregulated (IUU) fishing (Petrossian \& Pezzella, 2018); Process of } \\
\text { seafood substitution, short weighting, mislabeling and overtreatment of seafood upon } \\
\text { landing (Petrossian \& Pezzella, 2018); Rhino horn and live pet trafficking (Viollaz, } \\
\text { Graham, \& Lantsman, 2018); Rhino poaching (van Doormaal, Lemieux, \& Ruiter, } \\
\text { 2018); Waste crime (Tompson \& Chainey, 2011); Waste crime script for tyre } \\
\text { collection (Baird, Curry, \& Cruz, 2014); Wildlife crime (Lavorgna, 2013); Wildlife } \\
\text { trafficking (Lavorgna, 2014c). }\end{array}$ \\
\hline
\end{tabular}




\begin{tabular}{|l|l|}
\hline & $\begin{array}{l}\text { Doping (Vakhitova \& Bell, 2018); Crimes linked to wind farm creation (Caneppele, } \\
\text { Riccardi, \& Standridge, 2013); Graffiti (Cornish, 1994); A hypothetical capable }\end{array}$ \\
$\begin{array}{l}\text { Other crime } \\
\text { guardian script (Leclerc, 2014); A hypothetical handler script (Leclerc, 2014); A }\end{array}$ & $\begin{array}{l}\text { hypothetical place manager script (Leclerc, 2014); Intervention script of capable } \\
\text { guardians against crime in public settings (Leclerc \& Reynald, 2015); Negative } \\
\text { posting scenario (Samonas, 2013); Safety script (Leberatto, 2015); }\end{array}$ \\
\hline
\end{tabular}

Some of the identified crime types can be associated with multiple categories (e.g., fraud offenses and environment crime). Those are only included in one category to avoid duplicates.

Table 3. Synonyms of the term 'crime script' and number of publications in which they appear

\begin{tabular}{|l|c|}
\hline \multicolumn{1}{|c|}{ Synonym } & Number of publications \\
\hline Crime Script* & $328^{* *}(79 \%)$ \\
\hline Crime Commission Process* & $262(63 \%)$ \\
\hline Modus Operandi* & $182(44 \%)$ \\
\hline Scenario & $115(28 \%)$ \\
\hline Offender Behaviour* & $13(3 \%)$ \\
\hline \multicolumn{2}{|c|}{${ }^{*}$ appears in (Cornish, 1994b) } \\
**out of 416 selected studies
\end{tabular}

